\title{
Thickeners versus centrifuges - a coal tailings technical comparison
}

\author{
S Meiring PasteTech, Australia
}

\begin{abstract}
Both high-rate thickeners and dewatering centrifuges are used in the application of dewatering coal tailings. Both applications are well advanced and accepted as means to dewater coal. This paper compares a high-rate thickener to a solid bowl centrifuge with respect to numerous process, mechanical, electrical, control, layout and operator variables. Process variables include feed, effluent water discharge, retention time, and centrifuge cake moisture/thickener underflow percent solids. A comparison of a $33 \mathrm{~m}$ diameter thickener and a $1.117 \mathrm{~m}$ diameter solid bowl centrifuge with respect to $g$ square meters is shared.

The suitability of the dewatering application is governed by the properties of the resultant solids mixture. Different ash tailings, particularly those containing clay, presented a challenge to both the operations of the thickener and the centrifuge. A holistic view to the entire process is required.
\end{abstract}

\section{Introduction}

The coal and oil sands industries utilise thickeners and centrifuges to dewater tailings slurry. Both dewatering applications have been in the industry for over 60 years and are well-accepted dewatering methods.

While each application is uniquely different, a common criteria applies, namely to dewater fine solids to meet an acceptable transport criterion. While numerous dewatering bench scale and pilot plant tests are utilised to determine the extent of the dewatering, a number of fundamental differences in the dewatered solids can be found.

A description of a centrifuge and a thickener are provided together with a look at the different process variables that have an impact on the applications.

The technical analysis and comparison of the applications in delivering a paste has at times fallen short of a high acceptable standard. Each application requires an extensive process review. Furthermore, mechanical, electrical, control and operator considerations must be addressed. This paper addresses the more important process differences between a centrifuge and a thickener.

A $33 \mathrm{~m}$ diameter thickener and a $1.117 \mathrm{~m}$ diameter solid bowl centrifuge are compared. A table of the comparisons and considerations influencing the selection decision is provided.

\section{$2 \quad$ Australian background}

Xstrata's Bulga Coal Preparation Plant in New South Wales was the first Australian operation to install a paste thickener. Rio Tinto's Clairmont Coal Preparation Plant in Queensland was the second. Both these operations pump thickened underflow slurry.

Bulga is operating an $18 \mathrm{~m}$ diameter, $6 \mathrm{~m}$ sidewall depth paste thickener with $2 \mathrm{MNM}$ drive torque design. Its design capacity is $100 \mathrm{t} / \mathrm{h}$ dry solids with a target underflow density of $50 \% \mathrm{w} / \mathrm{w}$ solids and 300 Pa yield stress. Flocculant consumption was higher than anticipated and averaged $146 \mathrm{~g} / \mathrm{t}$ (Bickert \& Langer 2012).

In contrast, Clairmont's operation produced a paste containing $50 \%$ solids with $19 \mathrm{~g} / \mathrm{t}$ flocculant. The yield stress was below $100 \mathrm{~Pa}$ (Bickert \& Langer 2012). 
Recently Bloomfield's Rix's Creek Coal Preparation Plant in New South Wales installed a thickener centrifuge dewatering circuit. To date, the cake quality and handleability have exceeded expectations with

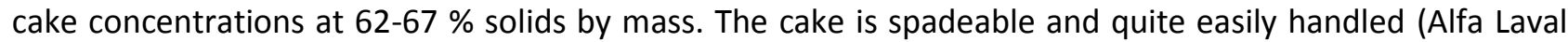
n.d.).

\section{Centrifuges}

A centrifuge consists of two horizontal concentric rotating elements contained in a stationary housing. The outer rotating bowl contains the solids and is progressively tapered to allow the solids to be discharged from a smaller radius than the liquid. The inner component is a screw conveyor with blades shaped to fit closely to the contour of the bowl in order to transport the separated solids to the point of discharge.

Feed slurry is introduced into the conveyor hub by pump or gravity flow. Distribution ports disperse the slurry into the rotating bowl. The solids then settle through the liquid pool within the bowl. A slight differential speed between the rotation of the bowl and the conveyor enables the solids to be conveyed continuously along the bowl wall, out of the liquid pool, and up the inclined tapered drying beach to discharge ports. The clarified liquid discharges continuously in the opposite direction over pre-set adjustable weirs. Flocculant can be utilised to assist with the agglomeration of the fine particulates.

Extended clarification zones are provided with bowl length to diameter ratios up to $4: 1$. The extended length of the centrifuge assists with longer retention times, which enhances the recovery of solids and final moisture content.

In a screen bowl centrifuge (which is similar to a solid bowl, but has a screen section on the end of the cone), as depicted in Figure 1, the conveyor moves the solids onto a screen section where centrifugal force removes remaining water. The solids in the screen section can be washed, further removing ultra-fine particulates, which in the case of coal typically has higher ash values.

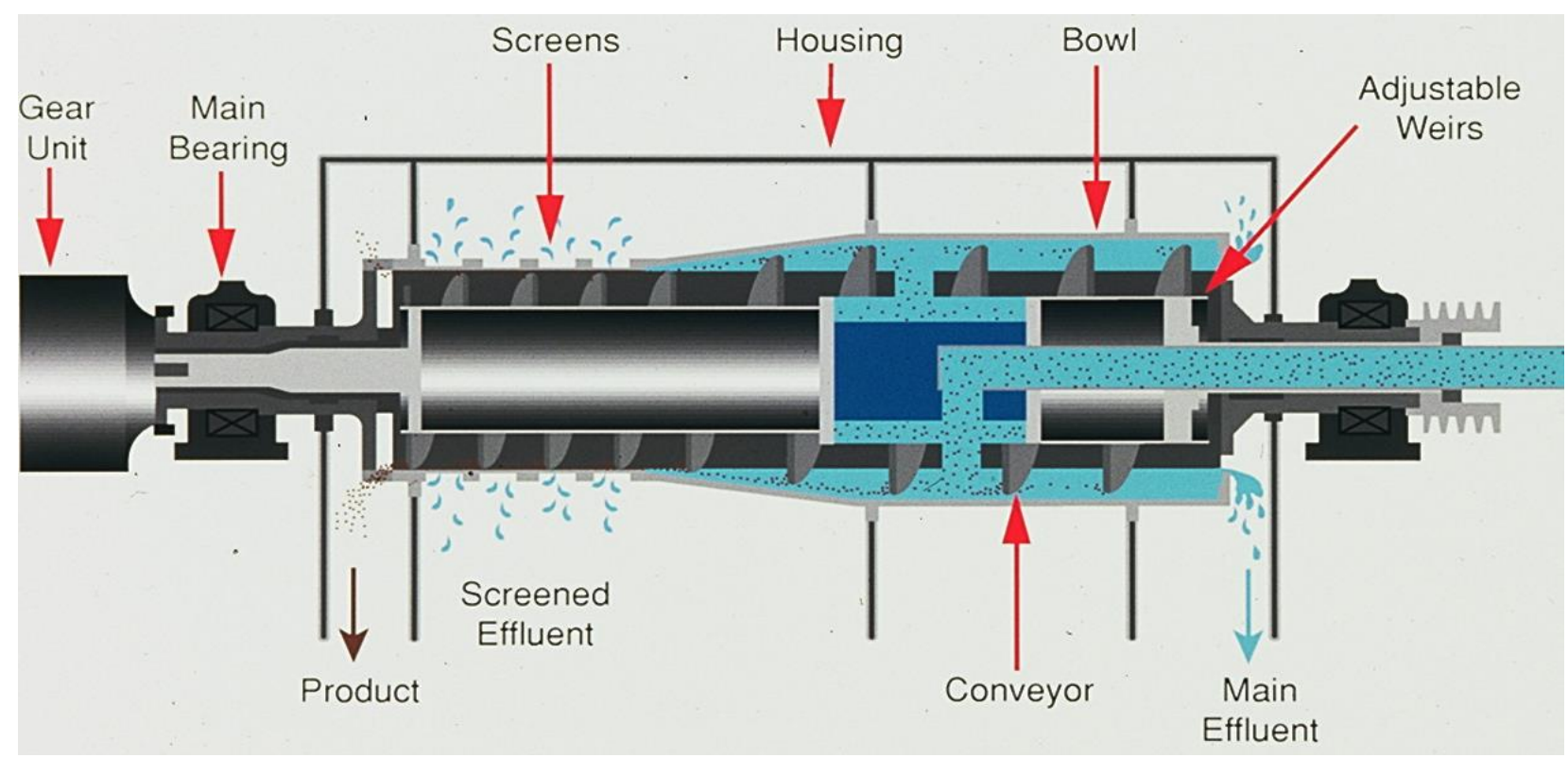

\section{Figure 1 Screenbowl centrifuge}

\section{$4 \quad$ Thickeners}

A thickener consists of a round tank, feedpipe, feedwell, rake drive and mechanically operating rakes. The inlet stream to a thickener, usually a dilute slurry, is known as the thickener feed, while the decanted solution is referred to as the overflow. The concentrated solids slurry pumped away from the thickener discharge cone is referred to as the underflow (Figure 2). Also shown is the feedwell, which dissipates the energy in the feed stream so as to cause the feed to enter the tank in a relative quiescent condition and 
thereby prevent circulation currents within the thickener. The feed well design by some vendors caters for a feed well distribution cone or plate, which ensures distribution of the flocculated feed evenly into the thickener.

The thickener provides the holding retention time and area to produce settled solids at a much higher concentration than the feed. The sloped bottom and rakes assist movement of the settled solids towards the discharge point, maintaining a degree of fluidity in the thickener to ensure hydraulic continuity and increased underflow solids concentration by providing channels to escape from the settled solids. Sometimes vertical pickets are fixed to the rake arms to provide additional paths for water to channel its way upward to the overflow.

An overflow launder collects the clarified liquid around the tank periphery.

Depending on the application, different height to diameter ratios as well as floor slopes can be provided.

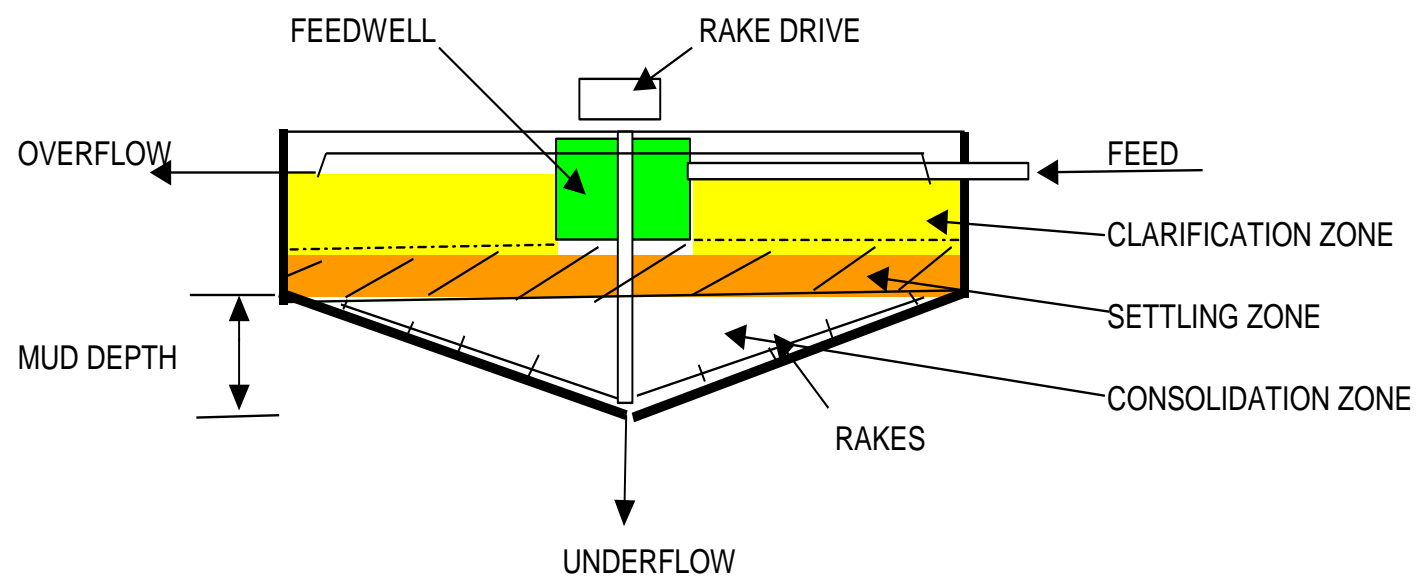

Figure 2 High-rate thickener

\section{$5 \quad$ Sizing thickeners and centrifuges}

Settling and pilot plant tests are used to predict the underflow percent solids content from a thickener. Tests must be performed to assess the theoretical maximum limit of water that can be removed from the underflow. The water permeability rate through the thickened bed controls the final underflow percent solids. Unit area per tonne per day is the common sizing approach, however, it is not uncommon for coal tailings thickeners to be sized on the rise rate of released water. The solids settling velocity has to be greater than the rise rate, or else the solid liquid separation will not occur. Clarifiers, which focus on the overflow liquid clarity, are always rise rate limited, however, thickeners, which focus on the underflow solids concentration, are generally not. The accepted practise for coal tailings is to ensure that the rise rate of water is 0.5 times the settling rate of the finer particulates.

Centrifugal and pilot plant spin tests are used to predict the cake moisture content from a centrifuge. g-force (speed and diameter), retention time and cake volume are used to determine the centrifuge diameter and length. During spin tests, the final moisture of the tailings after prolonged centrifugation, termed the Non Centrifugable Moisture, must be determined. This percentage is then compared to the required cake moisture content.

Both thickener and centrifuge results must be compared with a view on the entire system, which may include pumping, conveying, trucking and finally deposition. The paste properties must be dictated by the applications after the thickener or centrifuge. 


\section{Sedimentation}

In its simplified form, there is a direct relationship between the size of a spherical particle and its rate of fall in a stationary liquid. This is provided by Stokes' law (Lamb 1945):

$$
V=D^{2} g(P s-P I) / 18 n
$$

Where:

$$
\begin{aligned}
& \mathrm{V}=\text { settling velocity }(\mathrm{cm} / \mathrm{s}) . \\
& \mathrm{D}=\text { spherical particle diameter }(\mathrm{cm}) . \\
& \mathrm{g} \quad=\text { acceleration due to gravity }=9.807 \mathrm{~m} / \mathrm{s}^{2} . \\
& \mathrm{Ps} \quad=\text { particle density }\left(\mathrm{g} / \mathrm{cm}^{3}\right) . \\
& \mathrm{PI} \quad=\text { liquid density }\left(\mathrm{g} / \mathrm{cm}^{3}\right) . \\
& \mathrm{n} \quad=\text { liquid viscosity }(\mathrm{cp}) .
\end{aligned}
$$

For example, the free falling velocity of a 16 micron particle with specific gravity $=3$ in water at $20^{\circ} \mathrm{C}$ is approximately $1 \mathrm{~m} / \mathrm{h}$.

However, in a centrifuge the formula changes to include the rotational speed of the bowl.

$$
V=r \omega^{2}(P s-P I) D^{2} / 18 n
$$

Where:

$r \quad=$ distance of particle from centreline of rotation (metres).

$\omega=$ rotational speed (radians/sec) .

The above formula clearly indicates that the separation velocity is influenced by the rotational speed and the particle density. Therefore high-speed centrifuges help to increase the separation efficiency.

The role of flocculant is to increase the effective particle size and thus increase the settling rate and overcome the net upward velocity (rise rate).

\section{7 g-force}

Centrifugation follows the same laws as a gravity thickener, except that in place of one gravity force in the thickener, the centrifuge generates a centrifugal force, which is from a few hundred to several thousand times greater than the force of gravity.

While the capacity of a thickener is a function of its surface area, the capacity of a centrifuge is a function of the liquid surface area multiplied by the ' $\mathrm{g}$ ' force. The ' $\mathrm{g}$ ' force will be equivalent to the number of times that the centrifugal force within the centrifuge is greater than the earth's gravity.

Referring to Figure 3 , it can be seen that a $33 \mathrm{~m}$ diameter thickener has a capacity factor of 855 ' $\mathrm{g}$ ' square metres. A $1.117 \mathrm{~m}$ diameter centrifuge, has a diameter of the inner surface of the liquid layer equivalent to approximately $730 \mathrm{~mm}$ and clarified effluent length of $1.636 \mathrm{~m}$, will have a surface area of $3.8 \mathrm{~m}^{2}$. Running at a speed of $750 \mathrm{rpm}$ will result in 856 ' $\mathrm{g}$ ' square metres, which is equivalent to a $33 \mathrm{~m}$ thickener.

While the sedimentation rate of settling particles in water is a function of its specific gravity and size, enhancing these rates can be overcome by adding a flocculant, removing excess air and in some cases adding coarse particles. 


\section{3 m High Rate Thickener}

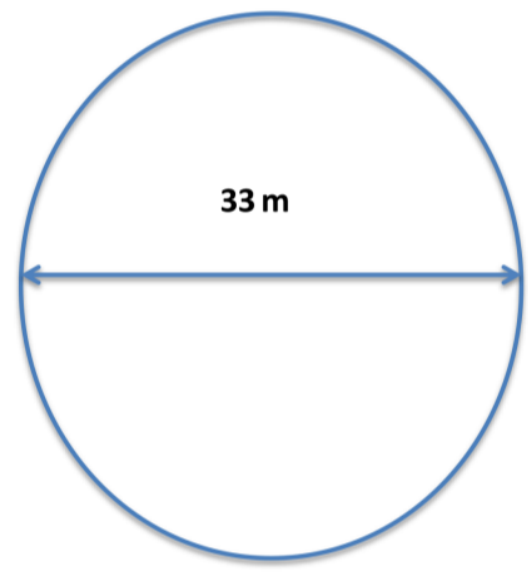

$$
\begin{aligned}
& \text { Area }=\pi R^{2}=3.14 \times 16.5 \times 16.5 \\
& 855 \mathrm{~m}^{2}
\end{aligned}
$$

\section{Gravity $\quad 1 \times \mathrm{g}$ \\ Capacity Fact $8631 \times 1$}

855.3 "g" m²

\subsection{7 m Diameter Solid Bowl Centrifuge}

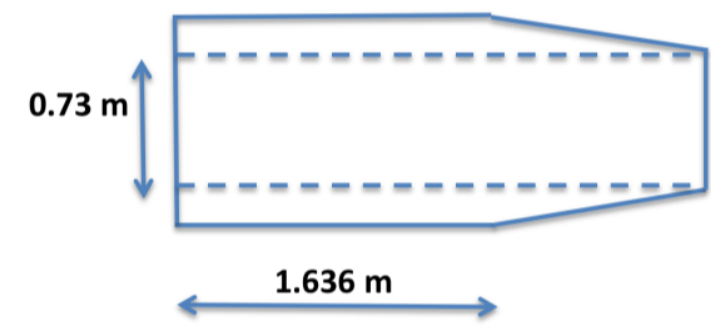
Area $=\pi \times D X L \quad=3.14 \times 0.73 \times 1.636$
$3.8 \mathrm{~m}^{2}$
G force
$=n^{2} \times \theta / 1800$

228.1

Capacity Fact $228.1 \times 3.8$

856 "g" m²

Where:

$\mathbf{n}=$ bowl speed (RPM) - 750

$\boldsymbol{\theta}=$ inside bowl diameter $(\mathrm{m})$

\section{Figure 3 ' $g$ ' square metres comparison}

While theoretically the clarification capacity in terms of ' $\mathrm{g}$ ' square meters of the $1.117 \mathrm{~m}$ diameter centrifuge is equivalent to a $33 \mathrm{~m}$ diameter thickener, a number of other process issues must be considered.

\section{$8 \quad$ Feed}

A coal tailings thickener feed percent solids typically falls in a range of 2 to $9 \% \mathrm{w} / \mathrm{w}$ solids. Typically, a lower feed percent solid produces faster settling rates, moreover, as the particle size of the feed becomes finer, the optimum feed solids concentration tends to decrease.

Recently in a report completed by the Australian Coal Industry Research Program (Bickert \& Langer 2012), it was found that the feed to a thickener greatly impacted the underflow percent solids. Paste thickening was found to be dependent on the coal seam material properties (ash and clays) fed to the thickener (Bickert \& Langer 2012). A Queensland sample had an $86 \mathrm{mg} / \mathrm{I} \mathrm{Ca}^{2+}$ and $110 \mathrm{mg} / \mathrm{I} \mathrm{Mg}^{2+}$ in the liquid, while a New South Wales sample reported $12 \mathrm{mg} / \mathrm{ICa}^{2+}$ and $6.7 \mathrm{mg} / \mathrm{I} \mathrm{Mg}^{2+}$. The zeta potential for the Queensland sample was found to be between -5 to $-15 \mathrm{mV}$, while the New South Wales sample was larger at -17 to $-29 \mathrm{mV}$ (Bickert \& Langer 2012). It has been suggested that the higher bivalent cation concentration and lower zeta potential of the Queensland sample, permits better coagulation of particles in the feed well. The variable feed material from the different coal seams is believed to cause thickener product variations and in turn the required underflow density has not been obtainable.

It has also been apparent that during times when high amounts of coal are fed to the thickener, achieving an underflow solids concentration has been problematic.

It is prudent to point out that in a feedwell the objective is to create a homogenous bed with little classification of particles size, to achieve optimum performance. While in a centrifuge particles are quickly sorted by size and density. 
The following abstract taken from RA Triglavcanin, Outotec Pty Ltd paper 'The heart of thickener performance' is worth repeating.
"Delivering dilution water and mixing this water with incoming feed slurry, addition of flocculant, maximising flocculant-slurry interaction to build aggregate size, unabsorbed flocculant percentage, volume average of solids volume fraction, momentum dissipation ratio, dilution recycle ratio, volume average shear, max shear rate at exit, aggregate size on exit, uniform discharge profile and more - all of these need to occur in the right order and in the right proportions within the thickener feedwell, the heart of thickener performance." (Triglavcanin 2008)

This suggests that there are a number of requirements that need to be met for 'acceptable' thickener feed and one could argue that thickener feed conditioning be a completely separate application added to the development of a flow sheet.

In a centrifuge, as the feed becomes more dilute, sedimentation is more effective due to reduced hindered settling. When the feed is too dense, the particles are influenced by neighbour reactions and consequently the entire slurry settles at one velocity independent of the particle size. Feed to a centrifuge can vary from anywhere between $2-60 \%$ solids. In some applications, hydrocyclone underflow reports directly into a centrifuge.

Unlike a thickener, the gravitational acceleration transferred in the centrifuge bowl, does not require such a demanding feed preparation. Recent centrifuge work has improved the feed acceleration via vanes, baffles and feed distributors. These enhancements have increased the tangential speed of the entering slurry, producing uniform circumferential distribution and allowing for greater capacity.

The hydraulic capacity of the $33 \mathrm{~m}$ thickener and a $1.117 \mathrm{~m}$ diameter centrifuge are limited in coal tailings applications. Thickener volumetric throughputs are typically limited by the size of the feedwell, which in turn is sized based on a required retention time. For comparative purposes, a $33 \mathrm{~m}$ thickener has a hydraulic capacity of $2,000-3,000 \mathrm{~m}^{3} / \mathrm{h}$ or more, while a $1.117 \mathrm{~m}$ diameter centrifuge has a hydraulic capacity of approximately $180-200 \mathrm{~m}^{3} / \mathrm{h}$. Similarly, a $33 \mathrm{~m}$ thickener could treat approximately $100-200 \mathrm{t} / \mathrm{h}$ solids, while a $1.117 \mathrm{~m}$ diameter solid bowl centrifuge could dewater approximately 40-70 t/h solids (triple lead conveyor scroll). Test work would be required to confirm the solid and liquid throughputs for both applications.

Cake form time in the centrifuge is critical and if solids recovery is not an issue, cake dryness can increase with increased feed solids. Analysis of the particle size distribution is important, as coarser particles dewater to a higher dryness due to higher permeability and better drainage.

\section{Retention time - volume only}

Coal tailing thickeners are most frequently designed in terms of water handling capacity.

The retention time of the two applications will differ dramatically if they were treating $181.6 \mathrm{~m}^{3} / \mathrm{h}$ of coal tailings.

The solids retention time for the centrifuge with a dewatering volume of approximately $1 \mathrm{~m}^{3}$ (estimated weir plates at $60 \%$ ) will be in the order of 20 seconds.

The solids retention time for the thickener with a dewatering volume of approximately $3,339 \mathrm{~m}^{3}(3 \mathrm{~m}$ sidewall height, 1:6 floor angle) will be approximately 18 hours.

Clearly a thickener provides more retention time for particles to work their way into the consolidation zone and combine with the underflow paste. Furthermore, and in some fine particle applications, an amount of compression time to meet an underflow concentration is required.

It is also important to note that some vendors do not use retention time predictions for thickener scale-up and design. The extrapolation from one solids loading and bed depth combination (in a pilot unit) to 
another (a full-scale thickener) has been found to be an inherently risky scale-up strategy. It is a known fact that bed permeability changes with changes in bed depth, and underflow densities do not increase linearly with bed height.

When the centrifuge is used as a classifier, the centrifugal action works similar to that of a classifying hydrocyclone. Fine slow-settling particles are swept out of the centrifuge with the liquid effluent before they have time to sink to the bowl wall.

\section{Particle sizes and the influence of $\mathbf{- 4 5}$ micron fines}

In centrifuge applications, a large portion of the ultra-fine material, in particular the -45 micron material, reports with the effluent. In a thickener however, with a much longer retention time, a larger fraction of the -45 micron material is captured in the underflow. According to Stokes' law, should the coal tails' particle size reduce from 45 to 10 micron, the required settling rate would decrease from $0.55-0.272 \mathrm{~mm} / \mathrm{s}$. Within the small area of the centrifuge, the ultra-fine particles do not have sufficient retention time to settle.

Furthermore, the cake solids concentration from a centrifuge is heavily related to the percentage of -45 micron material in the feed. It is therefore imperative to understand the percent of -45 micron material in the feed and cake to answer the simple question 'whether a centrifuge would capture the required fines?'.

While large quantities of reagents have improved the recovery of fines, the costs of the reagents sometimes do not make the selection of the centrifuge viable. Some centrifuge applications require very little reagent, however, these are in most cases, plants that do not recover ultra-fine material.

A minimum of $15-20 \%$ by weight of -20 micron material is required for homogenous non settling pipeline transport (Aldea \& Connolly 2014). The fines slurry in contact with the pipe wall helps reduce the friction and pipe wear for pipeline flow.

Should centrifuge dewatering be selected as a means to dewater coal tailings, and pumping selected as a means to transport the cake, it is strongly suggested that loop pump tests of the cake (which typically contains lower quantities of fine particles) and different rheological properties be investigated.

It is also important to understand, that the largest and smallest particles in any given system are likely to vary by a factor of 10 to 100 , especially at the finer end of the range. Care should therefore be taken when the word 'average' is used to highlight a particle size, as this may not be indicative of the distribution.

\section{Recovery}

In a centrifuge there is a trade-off between quality and quantity (Leung 1998). Centrifuges are either set up for cake dryness or solids recovery via effluent ports that set the pool depth. A low pool indicates a target for cake dryness, while a deep pool typically aligns with improved recovery.

When referring to centrifuge recovery, the primary function of the centrifuge pool and volume are to permit the solids to compact. It is essential to minimise the hydraulic velocity through the pool in order to maximise the average settling force and exposed surface area. At first glance, these two functions appear to contradict each other, however, in a centrifuge the solids, once captured, compact to their final density very quickly. This allows the machine time to clarify out the remaining solids in the effluent. This requires longer retention times and is severely affected by high flows. It is for this reason that centrifuges have diameter to length ratios of up to 1:4.

On the other hand, a thickener tends to be more forgiving when increases in flow and solids occur. With the much longer retention times, thickeners can accommodate sharp fluctuations in hydraulic flows far better than centrifuges, resulting in better recoveries. 
Majority of thickeners installed on coal tailings plants have recoveries in the range of $96-99 \%$ whereas solid bowl centrifuge recoveries tend to be in the range of $90-95 \%$.

Furthermore, the addition of flocculation as a means to promote the settling of particles in thickeners is well established. Flocculants have reduced the diameter of thickeners, and promoted better recovery. On the other hand, flocculant addition in some high-speed centrifuges has resulted in mechanical shear and proved insignificant. The manner in which the flocculated particles enter the centrifuge pool will determine the extent of the recovery. In a high-shear environment, delicate 'flocs' will break and result in poor recoveries and possibly higher flocculant consumption.

Typically the solids recovery and cake dryness both decrease with the increase in solids throughput in a centrifuge.

\section{Underflow solids (thickeners)/cake moisture (centrifuges)}

While thickeners are continuous units like centrifuges, the thickener underflow withdrawal rate can be initiated at different times, at different percent solids or conditions based on the operating philosophy of the plant. This is not always the case with centrifuges. In some cases the thickener underflow can be recirculated back into the thickener while fresh feed is entering the thickener. On the other hand, a centrifuge cake cannot be initiated at different times and does not have the capacity to produce a range of cake percent solids and recirculate the cake. Centrifugal forces (bowl speed and diameter) are typically set and therefore do not have the flexibility of a typical thickener underflow system.

The g-forces produced by a fixed speed centrifuge tend to vary little. This typically produces more consistent cake moisture than a thickener underflow solid (based on the same feed material and particle size distribution).

The coal tailings cake moisture produced from a centrifuge is in general, closer to the non-centrifugal moisture, whereas, the percent solids from a thickener is not as close to the theoretical maximum water limit.

A thickener has a greater range of underflow solids percentages, while the centrifugal force of a fixed speed centrifuge reduces the range of cake moisture content. A variable speed drive would need to be fitted to the drive motor on a dewatering centrifuge, however, in most applications the benefits have proven marginal.

Creating a paste can be extremely difficult as pointed out in an ACARP Report C18042 (Bickert \& Langer 2012).

"The variable feed material caused the thickener product variations and at times it was not possible to obtain the required underflow density for further handling which were above the design target of $50 \%$ underflow solids."

While the New South Wales coal seams generally have a higher clay content than the Queensland coal seams, it is possible that the problems with creating paste lies in the composition of the feed entering the feedwell. Data obtained from one coal tailings operation and seam therefore cannot be utilised on another coal operation.

Installed thickeners will have an operating point on the yield stress curve of a particular seam, which will move up or down depending on nature and composition of the tailing seams and how the thickener is operated. The underflow solids of installed thickeners will be inhibited by the yield stress of the material, whereas in a centrifuge, the retention time will not allow the yield stress to build to unmanageable strengths.

Lastly, clays within a centrifuge will undergo greater shear than a thickener owing to the mechanical nature of the bowl and scroll. This may cause the particles to swell and creates a more stiff structure, increasing the viscosity. Centrifuges have been known therefore to shear thicken negatively charged clay particle slurries. 


\section{Other important comparisons and considerations}

Table 1 highlights the differences between a $33 \mathrm{~m}$ thickener and a $1.117 \mathrm{~m}$ diameter centrifuge.

\section{Table 1 A $32 \mathrm{~m}$ diameter thickener versus a $1.117 \mathrm{~m}$ diameter centrifuge}

\begin{tabular}{|c|c|c|}
\hline Item & Thickener & Centrifuge \\
\hline \multicolumn{3}{|l|}{ Process } \\
\hline 'g' square metres & Equal & Equal \\
\hline Tonnage (dry solids) & Greater & Less \\
\hline Hydraulic limits (water) & Greater & Less \\
\hline Retention time & Longer & Shorter \\
\hline Underflow percent solids/cake moisture & Lower & Higher \\
\hline Yield stress (average) & Lower & Higher \\
\hline Overflow/effluent solids & Lower & Higher \\
\hline Feed preparation - 'conditioning' & Greater & Less \\
\hline Flocculant & Lower & Higher \\
\hline Upsets - feed fluctuations & Higher & Lower \\
\hline Shutdown time/mishaps & Long & Short \\
\hline \multicolumn{3}{|l|}{ Mechanical } \\
\hline Pumping paste (-20 micron) & Yes & No \\
\hline Shear thinning required & More & Less \\
\hline Maintenance (wear rate)* & Less & More \\
\hline Pipe runs & More & Less \\
\hline Excess torque & More & Less \\
\hline Structural steel & More & Less \\
\hline Installation time & Long & Short \\
\hline Electrical - power & Low & High \\
\hline Control - instrument checks & Equal & Equal \\
\hline Layout - real estate & More & Less \\
\hline \multicolumn{3}{|l|}{ Operator input } \\
\hline Stairways & More & Less \\
\hline Changing conditions (upsets/donuts) & More & Less \\
\hline Reaction time & Slow & Rapid \\
\hline Inspection or operator time & Long & Short \\
\hline
\end{tabular}

* Test work required. Centrifuges can be extremely abrasive 


\section{$14 \quad$ Factors to consider}

There are advantages to combining thickeners and centrifuges to treat coal tailings. The combination will allow for better hydraulic capacity and overflow clarity of the thickener, as well as the higher cake solids achievable with a centrifuge.

A number of technical factors (beyond economics) need to be addressed before a centrifuge or thickener is selected as a means of dewatering.

There are fundamental differences between the applications. Feed characterisation of the material must be thoroughly assessed.

The following important information must be considered:

1. The rheological properties and their impact on the design of dewatering application, paste transport and tailings storage facility.

2. Both the capital and operating costs of the dewatering units. Typically, installation costs for a $33 \mathrm{~m}$ diameter thickener compared to a $1.117 \mathrm{~m}$ diameter centrifuge will be higher, however, more than one centrifuge may be required on a like for like tonnage comparison. Reagent and energy costs need to be carefully scrutinised.

3. Consultants and engineers with experience in dewatering must assess test results and be involved in the development of dewatering applications. This will ensure the approach includes historical data, worldwide experience and treatment of modern theory. Pilot thickener plants have limitations (Meiring 2014) which explains that in some applications red herrings do occur.

4. Fines and coarse particles have different settling and dewatering rates. It may indeed be advantageous to treat a fraction of particles in a particular size distribution using one application, and another application treating the remaining size fraction. The products of the different sizes could then combine to achieve the desired deposition properties.

5. Liquification of the solids following dewatering.

6. Vendor technological advancements - these may include thickener feedwell advancements and the development of centrifuge wear protection.

\section{Conclusions}

In general, centrifuge cake solids concentrations are typically closer to the theoretical solids limit than the underflow solids mass concentration of thickeners.

Thickener underflow solids and yield stress values tend to be lower than centrifuge cake solids. This is exemplified by upset or bogged conditions where a thickener may need to be taken off-line for many hours.

A $33 \mathrm{~m}$ diameter thickener would be capable of treating a far greater volume of water and solids than a $1.117 \mathrm{~m}$ diameter centrifuge. Furthermore, the overflow quality of a thickener would be more superior to that of a centrifuge effluent.

A centrifuge cake would be minus a large portion of -45 micron material, which would still need to be treated. The slurry may create rheological pumping challenges over long distances.

Creating a paste from a number of different coal seams in a thickener is challenging. The variable feed material from the different coal seams can cause thickener underflow variations. Reaching the desired underflow density has not been possible on some coal tailings plants where clays are present.

Careful scrutiny of dewatering test work is required.

Both upstream and downstream aspects of the flow sheet, as well as the actual dewatering process have to be considered during technical studies. Ideally the design sequence should start with downstream process requirements and finish with the dewatering application. 


\section{References}

Aldea, CM \& Connolly, K 2014, 'Successful recipes for mine paste backfill', in RJ Jewell, AB Fourie, PS Wells \& D van Zyl (eds), Proceedings of the 17th International Seminar on Paste and Thickened Tailings, InfoMine Inc., Vancouver, pp. 341-354.

Alfa Laval n.d., No more new tailings dam, Rix's Creek Case Story, Alfa Laval, Huntingwood.

Bickert, G \& Langer, B 2012, Maximising water recovery in an operating paste thickener, ACARP report C18042, Australian Coal Research Limited, Brisbane.

Lamb, H 1945, Hydrodynamics, Dover Publications, New York.

Leung, WW-F 1998, Industrial centrifugation technology, McGraw-Hill, New York.

Meiring, S 2014, Lessons from Thickener Pilot Plant Testing: Experiences Shared, Section 3.5 Anomalies in results page 9.

Triglavcanin, RA 2008, 'The heart of thickener performance', in AB Fourie, RJ Jewell, PT Slatter \& A Paterson (eds), Proceedings of the Eleventh International Seminar on Paste and Thickened Tailings, Australian Centre for Geomechanics, Perth, pp. 63-82. 
